\title{
Esse Mundo É Dos Loucos e Azyllo Muito Louco. Razão e desrazão em tempos sombrios
}

Maria Ignês Carlos Magno

Doutora em Ciências da Comunicação pela ECA-USP. Professora do mestrado em Comunicação da Universidade Anhembi Morumbi e da Fundação Escola de Sociologia e Política de São Paulo. E-mail: unsigster@gmail.com

Resumo: A proposta da resenha é a de apresentar dois filmes que marcaram os anos 1960 e 1970. Esse mundo é dos loucos (1966), de Philippe De Roca e Azyllo muito louco (1970), de Nelson Pereira dos Santos. Em ambos os filmes a loucura é o tema central, mais propriamente, a tênue linha que separa a loucura da sanidade. A ideia central é a de mostrar como os autores se utilizam da ficção para provocar reflexões sobre tempos e acontecimentos históricos.

Palavras-chave: Cinema; história; ficção; realidade.
Abstract: The purpose of this review is to present two films that marked 1960's and 1970's. Le Roi de cœur (1966), by Philippe De Roca and Azyllo muito louco (1970), by Nelson Pereira dos Santos. In both movies the madness is the focus, rather, the fine line that separates madness from sanity. The central idea is to show how the authors use fiction to provoke reflections on time and historical events.

Keywords: Cinema; history; fiction; reality.

Rever o filme Esse mundo é dos loucos (1966) de Philippe De Broca nos leva não só a relembrar essa comédia pacifista que tanto sucesso fez entre uma geração antiguerra, mas rememorar o que foram aqueles anos no mundo todo, e no Brasil, em particular. É impossível não lembrar o filme Azyllo muito louco (1970) de Nelson Pereira dos Santos e o seu significado para a mesma geração que vivia o Brasil dos generais. E uma pergunta pode ser feita: por que pensar a razão e a desrazão nessas duas comédias? Uma primeira resposta é a de que em ambos os filmes, a loucura é o tema central. A outra é a forma como os autores se utilizam da ficção para provocar a reflexão sobre acontecimentos e épocas. Philippe De Broca situa sua história no final da Primeira Guerra, 1918, para colocar em discussão a década de 1960, e Nelson Pereira dos Santos escolhe o conto O Alienista de Machado de Assis, 1882, para pensar os anos 1970 quando o Brasil já vivia a ditadura militar instaurada em 1964. Finalmente, porque esses autores ao buscar na realidade as bases para a ficção nos permitem conhecer e discutir esses tempos sombrios. 


\section{OS FILMES: ENTRE A LOUCURA E A SANIDADE. LIMIARES.}

\subsection{Esse mundo é dos loucos.}

A história de De Broca ocorre em 1918 quando o regimento do soldado Charles Plumpick, (Alan Bates) chega a Merville, um vilarejo ao norte da França próximo da fronteira com a Bélgica. Plumplick especialista em pássaros (ornitólogo) é confundido com um especialista em bombas e enviado ao vilarejo para desativar uma bomba deixada pelos alemães que estão se retirando da cidade. Ao chegar, ele percebe que os moradores do local foram embora e que a cidade foi tomada pelos pacientes de um hospício. No hospício, Plumpick se intitula como "o rei de copas" (nome original do filme - Le roi de Coeur), é coroado rei pelos loucos e se apaixona por uma bela moça chamada Coquelicot (Geneviève Bujold), a trapezista do lugar. Dividido entre a sua missão e a alegria de viver dos novos amigos, Charles se pergunta: "quem são os loucos?". Com o final da guerra, quando o mundo volta a aparente normalidade, os moradores retornam para suas casas e os loucos voltam para o hospício, ou seja, para a casa deles. Apartados e novamente alienados da sociedade.

\subsection{Azyllo Muito Louco.}

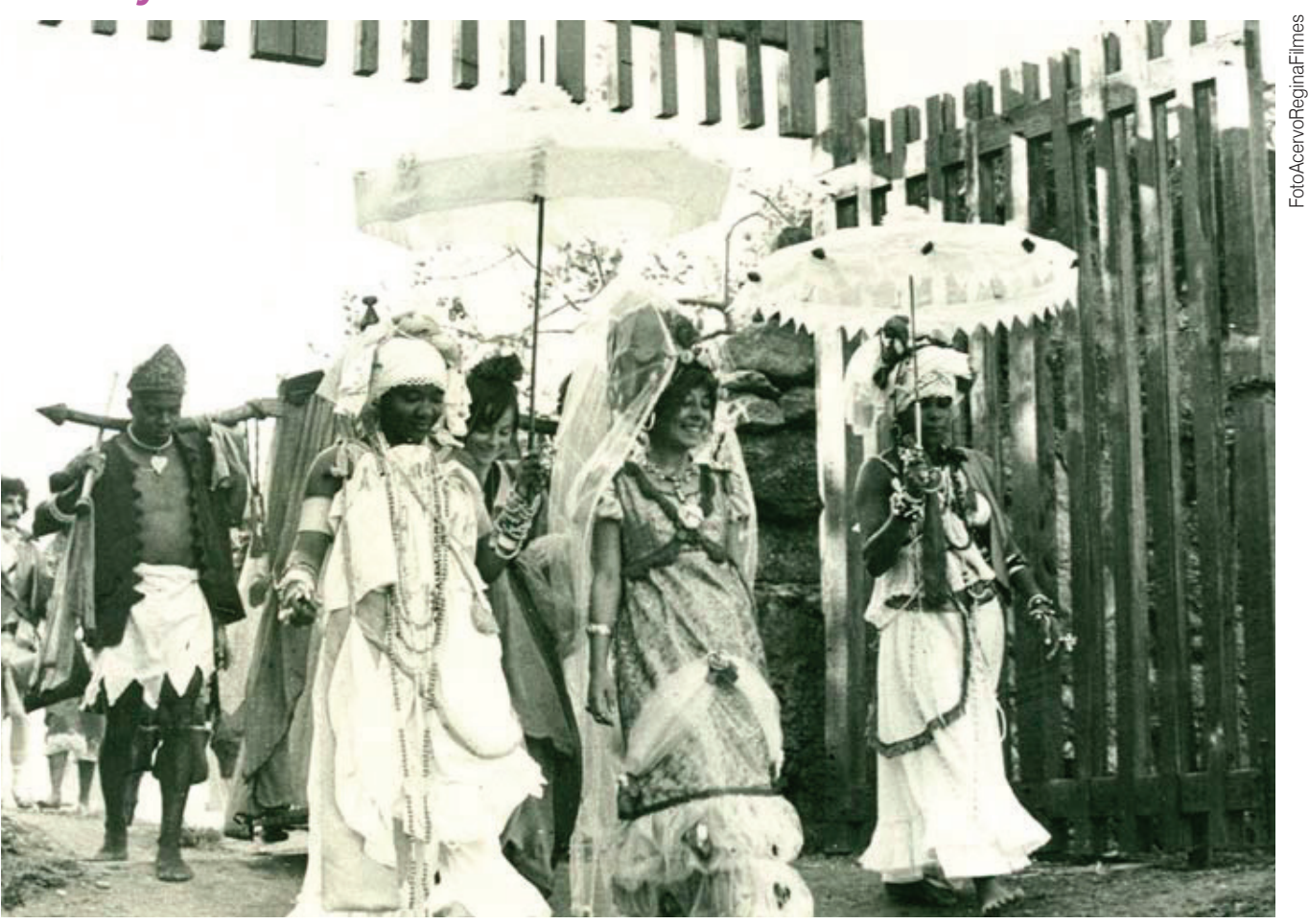

Na ficção de Nelson Pereira dos Santos, em Paraty, um homem anuncia a chegada do padre Simão à cidade. Na praia, uma multidão acompanha a chegada do padre. Dona Evarista lhe mostra a igreja da cidade. O padre realiza um 
sermão que atrai boa parte da população local. Em conversa com dona Evarista, propõe a construção de um hospício onde pretende realizar estudos sobre a loucura. Nas ruas da cidade, tenta arrecadar contribuições para a realização da obra enquanto, nas calçadas, alguns homens condenam sua atitude. O hospício da Casa Verde fica pronto e Simão solicita a presença do doutor Crispim ao local para fazer-lhe um convite. Ele pede que o doutor o ajude a administrar a casa. Muitos loucos se apresentam à Casa Verde, fato que levanta a suspeita de que muitos estão se internando apenas para fugir do trabalho e conseguir um prato de comida. Insatisfeitos, um grupo de pessoas pede auxílio a Porfírio e organiza uma revolta para destruir a Casa Verde e expulsar o padre, que não mostra resistência. Simão propõe a Porfírio e aos outros uma nova etapa em seus estudos. Apoiando-se no fato de que a maioria da população está internada no hospício, ele defende a ideia de que quem deve ser internado são as pessoas mentalmente "saudáveis". Porfírio e os demais aceitam a proposta de Simão e oferecem-se de cobaia para o novo experimento. Evarista e Crispim também se internam na casa. Parte do grupo, descontente com os métodos do padre, organiza uma revolta liderada pelo capitão Arcanjo, que prende Simão e liberta Porfírio, mantendo os demais presos na casa. O padre Simão diz que o tratamento chegou ao fim e todos são libertados, porém, conclui que ninguém está totalmente curado. Em reunião na Casa Verde, o padre é diagnosticado como louco. Dona Evarista tem um ataque e é acudida pelos outros. O grupo deixa a casa despedindo-se do padre, que continua a reger sua orquestra de loucos. (Cinemateca de São Paulo).

\section{DA FICÇÃO PARA A HISTÓRIA. REFLEXÕES.}

O filme de Philippe De Roca lançado em 1966, é ambientado nos anos 1918, quando a Primeira Guerra está no fim e os países perdedores estão em retirada. Um deles, a Alemanha. A Guerra que teve início em 1914 e seu final em 1918, entre tantos acontecimentos envolvendo todos os países do mundo, traz alguns fatos, que embora não estejam diretamente citados no filme, fazem parte do cenário ausente: um deles o massacre na Armênia pelos turcos em 1915; a Revolução socialista na Rússia, em 1917, colocando fim ao regime czarista; os Motins do exército francês e a Intervenção americana em 1918; ainda em 1918 ocorre a Revolução em Berlim, na Alemanha. Finalmente, o Armistício. Esses dados, além de exemplos de um contexto histórico mais amplo, um deles está diretamente relacionado ao filme: o assassinato de 50 doentes mentais durante a invasão do exército alemão a um hospital francês. Os internos vestiam uniformes de americanos mortos e andavam pelo campo quando foram fuzilados pelos alemães. Essa notícia publicada em um jornal francês na época deu origem ao argumento de Maurice Bessy e ao roteiro de Daniel Boulanger.

O período histórico escolhido por De Roca é 1918, mas se atentarmos para os anos 1965 e 1966, quando o filme foi feito, não é preciso muita pesquisa para saber o quanto a segunda metade da década de 1950 preparou terreno 
para os acontecimentos ocorridos nos anos 1960 em todos os continentes. Seguindo uma cronologia apresentada por Marc Ferro ${ }^{1}$, apenas para lembrar alguns fatos podemos citar que, em 1954 ocorre o fim da Guerra da Indochina e a Insurreição da Argélia. Dois acontecimentos que envolviam diretamente a política francesa e suas antigas possessões no Sudeste Asiático e na África. O fim da Península da Indochina, com as guerras de libertação, deu origem aos dois Vietnãs. Em 1956, ocorrem a crise de Suez e o nascimento do "terceiro Mundo". Em 1959 Fidel Castro e Che Guevara tomam o poder em Cuba. Em 1961 houve a Independência da Argélia do mando francês, a construção do Muro de Berlim e Martin Luther King surge como força política nos Estados Unidos, quando lidera entre os anos 1955 a 1967, a luta pelo fim da segregação racial no país. Em 1962, o mundo vive o auge da chamada Guerra Fria. A Crise de Cuba ou a Crise dos Mísseis alarmou o mundo com a possibilidade real de um confronto nuclear entre as superpotências Estados Unidos, sob o governo de Kennedy, e a URSS, sob o governo Kruschov.

O filme de De Broca não trata desses acontecimentos, mas esse é o cenário histórico da época em que produziu seu filme. 1965 é um ano emblemático para todo mundo: foi quando os Estados Unidos deixam de apoiar externamente o governo do ditador Ngo Dinh-Diem (Vietnã do Sul) e entram no conflito interno do Vietnã: na luta entra o norte socialista governado por Ho Chin Minh e o sul capitalista de Diem. É o ano em que crescem os protestos em toda a Europa e nos Estados Unidos contra a corrida armamentista entre EUA e URSS e contra a Guerra do Vietnã. 1965 foi o ano em que nascia a geração do "Faça amor e não a guerra”. Não por acaso o filme de Philippe De Roca, ou, um apelo pacifista contra a insanidade das guerras, foi sucesso e ficou meses em cartaz em diversas regiões do mundo. O filme lançado em 1966 não contava com o início das ações terroristas pós Guerra dos Seis Dias entre Israel e Palestina. Como De Broca não imaginava que os anos 1968 e as revoltas estudantis em Paris e Berlim pediriam, entre outras coisas, que a imaginação tomasse o poder.

O Brasil também vivia intensamente o clima dos anos 1960 em todos os segmentos da vida social, política e cultural, como acompanhava diariamente nos jornais os embates entre Ho Chin Minh e Kissinger, e a barbárie cometida nos campos de combates no Vietnã. Como parte do chamado "terceiro mundo" não podia ignorar os efeitos da Revolução Cubana e pensar numa via revolucionária para a América Latina. A intensidade reflexiva e a necessidade de compreender os problemas do Brasil, bem como o enfrentamento, que, nas palavras de Florestan Fernandes, não deveria fazer parte apenas do repertório teórico, mas vir acompanhado de um projeto e de uma ação fora interrompido pelo Golpe Militar de 1964 cortando abruptamente os vínculos que fundavam a criatividade da vida intelectual, deixando o espírito sem rumo, dizia Octávio Ianni na época.

1. FERRO, Marc. O século $\mathrm{XX}$ explicado aos meus filhos. Rio de Janeiro: Agir, 2008. p: $62-63$
Nesse duplo contexto histórico, Nelson Pereira dos Santos buscou o final do século XIX, mais propriamente 1882, ano da publicação do conto O Alienista, de Machado de Assis para ambientar seu Azyllo muito louco e provocar 
reflexões sobre a ditadura militar instaurada em 1964. Por que O Alienista? Como se apropriou do conto e traduziu Machado livremente para o cinema? Em entrevista concedida a Revista Estudos Avançados, Nelson Pereira explica:

Fiz uma adaptação livre do conto de Machado. Simão Bacamarte, o alienista, tornou-se no filme um padre cientista, acumulando à ciência o poder espiritual, o que o faz autoridade indestrutível. Ao lado de D. Evarista, a poderosa matrona da cidade de Serafim, pode realizar todas as experiências com o povo e a elite da terra. Uma metáfora da sociedade brasileira²

Metáfora de uma sociedade que sentia o peso da repressão política e do autoritarismo de um regime que invadia a vida de todos os brasileiros. $\mathrm{O}$ alienista de Machado de Assis é considerado, entre tantas análises e teorias já feitas, uma crítica corrosiva e bem-humorada aos mitos da ciência de sua época. Basta lembrar que é "em meados do século XIX que começam a aparecer as primeiras teses médicas sobre a alienação mental. E é em 18 de julho de 1841 que o imperador decreta a criação, na Praia Vermelha, no Rio de Janeiro, do Hospício de D. Pedro II, modelado de acordo com as instituições francesas organizadas por Pinel e Esquirol"3. Se a vila de Itaguaí aparece como uma alegoria da sociedade brasileira oitocentista, que vivia os embates entre os costumes ainda coloniais e as novidades da ciência de Simão Bacamarte, mais propriamente as novidades da psiquiatria do século XIX, que ao mesmo tempo que revolucionava a vida da Vila, mostrava a interferência dos médicos e das teorias cientificistas nas questões administrativas do Estado, a cidade de Serafim é o palco que o cineasta preparou para construir a metáfora de uma sociedade que via diariamente a interferência do Estado em todos os segmentos sociais, e os desejos de transformações políticas e culturais serem aos poucos silenciados, fosse como aqueles internados ou aprisionados nos cubículos da Casa Verde, fosse como os torturados nos porões dos presídios políticos que, em muitos casos, buscavam refúgio na loucura para sobreviver.

É visível no conto de Machado de Assis a sátira ao cientificismo aplicado ao estudo da loucura, mas essa história de loucos, segundo Alfredo Bosi4, "parece índice de uma outra dimensão, que inclui e ultrapassa a caricatura do perfeito alienista. Porque há nela o desenho claro de uma situação de força. Bacamarte não é, absolutamente, o tipo cientista maluco, marginal entregue à irrisão dos bem-pensantes. [...] Ele pode executar os projetos da ciência que o obseda. Seu status de nobre e portador do valimento régio transforma-o em ditador da pobre vila de Itaguaí". Para Bosi o eixo da novela é "o arbítrio do poder antes de ser o capricho de um cientista de olho metálico". Se retomarmos o conto e a adaptação feita por Nelson Pereira, fica claro o viés da leitura feita pelo cineasta. A Casa Verde é a Casa do Poder e é isso que Nelson Pereira pretende por em discussão no seu Azyllo muito louco: o poder e o arbítrio do poder.

Como no conto de Machado, o filme de Nelson Pereira ao ter "a partilha entre a razão e a desrazão como cerne da trama, a história toma ar de comédie d érreurs sobre a qual paira sempre a sugestão de ser o alienista o único
2.SANTOS, Nelson Pereira dos. Nelson Pereira dos Santos. Resistência e esperança de um cinema. In: Entrevista concedida a Paulo Roberto Ramos, Revista estudos Avançados, São Paulo, 21(59), 2007, p: 334.

3. MAURICY, Kátia. A razão cética. Machado de Assis e as questões de seu tempo. São Paulo: Companhia das letras, 1988 , p. 33.

4. BOSI, Alfredo. Machado de Assis e o enigma do olhar. São Paulo: Martins Fontes, 2007, p. 88-89. 
alienado" ${ }^{5}$. No conto, de acordo com a análise de Antonio Candido ${ }^{6}$ o alienista percebe que não há um só homem normal, imune às solicitações das manias, das vaidades, da falta de ponderação. "Analisando-se bem, vê que é o seu caso; e resolve internar-se, só no casarão vazio do hospício, onde morre meses depois. E nós perguntamos: quem era louco? Ou seriam todos loucos, caso ninguém o é?" Pergunta que aparece em ambos os filmes. Quem são os loucos? Quem são os sensatos? De que lado está a sanidade e a insanidade? Onde está a razão diante da loucura que está na essência das guerras e das ditaduras? No filme, o padre após ser diagnosticado como louco termina sozinho no hospício Casa Verde orquestrando seus loucos. No filme de Philippe de Roca, ao contrário, o protagonista abdica das armas e da vida considerada normal para viver entre os loucos do hospício de Merville ao lado de sua trapezista Coquelicot.

A discussão dessa linha tênue que separa a sanidade da loucura proposta pelas obras cinematográficas me levou a sugerir esses dois filmes para essa resenha, além, é claro, da leitura sempre contemporânea de Machado de Assis. E porque o contemporâneo, não necessariamente é o atual, na medida em que, tomando as palavras de Giorgio Agamben" "a contemporaneidade é uma singular relação com o próprio tempo, que adere a este e, ao mesmo tempo, dele toma distância; mais precisamente essa é a relação com o tempo que a este adere através de uma dissociação e um anacronismo. [...]”, é que essas obras nos interessam. Os autores das obras sugeridas ao exercitarem essa relação com os tempos distantes nos permitem pensar o tempo presente. Machado de Assis ambientou seu conto e loucura nos "tempos remotos" para criticar e discutir o Brasil de D. Pedro II; Philippe De Roca preferiu a Primeira Guerra para falar da loucura que foi aquela Guerra, e também do que viria depois - se pensarmos na pequena aparição do então soldado Hitler na batalha e filme -, e Nelson Pereira dos Santos retomou os "tempos remotos" do conto de Machado para pensar a loucura desencadeada pela ditadura militar dos anos 1970.

Como a poesia é sempre uma forma livre de nos fazer pensar e dizer sobre a vida, sugiro, entre tantas possibilidades de reflexão que os filmes trazem, uma sequência do filme Esse mundo é dos loucos em que um casal de louquinhos, vivendo sob a guerra, mas ignorando-a, conversam sobre a vida. $\mathrm{O}$ marido diz; "A vida é muito simples. Morrer é muito simples". E a mulher pergunta: "como se faz isso?" Ele diz: "é só fechar os olhos e nunca mais abrir". E ela olha para o céu e diz: "mas se eu fechar os olhos para sempre, nunca mais vou poder olhar para o céu”... conversa de loucos? Bons filmes e boa leitura.

5.Idem, p. 88

6. CANDIDO, Antonio. Vários escritos. São Paulo: Livraria Duas Cidades, São Paulo, 1977, p. 25.

7. AGAMBEN, G. O que é o contemporâneo? E outros ensaios. Santa $\mathrm{Ca}$ tarina: Argos, 2009, p. 59.

\section{REFERÊNCIAS}

AGAMBEN, G. O que é o contemporâneo? E outros ensaios. Santa Catarina: Argos, 2009.

BOSI, Alfredo. Machado de Assis e o enigma do olhar. São Paulo: Martins Fontes, 2007. 
CANDIDO, Antonio. Vários escritos. São Paulo: Livraria Duas Cidades, São Paulo, 1977.

FERRO, Marc. O século XX explicado aos meus filhos. Rio de Janeiro; Agir, 2008.

MAURICY, Kátia. A razão cética. Machado de Assis e as questões de seu tempo. São Paulo: Companhia das letras, 1988.

SANTOS, Nelson Pereira dos. Nelson Pereira dos Santos. Resistência e esperança de um cinema. In: Entrevista concedida a Paulo Roberto Ramos, Revista Estudos Avançados, São Paulo, 21(59), 2007, p. 334.

\section{Filmes:}

Esse Mundo é dos Loucos (Le roi de coeur)

Direção: Philippe De Roca

Roteiro: Daniel Boulanger

Argumento: Maurice Bessy

Fotografia: Pierre Lhomme

Música: Georges delerue

Gênero: Comédia

Ano: 1966

França-Itália

\section{Azyllo Muito Louco}

Roteiro e direção: Nelson Pereira dos Santos - adaptação do conto O Alienista de Machado de Assis

Fotografia: Luft Dib

Montagem: Rafael Justo valverde

Música: Guilherme Magalhães Vaz

Gênero: Comédia

Ano: 1970

Brasil 